\title{
Oridonin alters the expression profiles of MicroRNAs in BxPC-3 human pancreatic cancer cells
}

\author{
Zhifang Gui ${ }^{1}$, Shuquan $\mathrm{Li}^{1}$, Xing Liu' ${ }^{2}$, Bin $\mathrm{Xu}^{3}$ and Jian $\mathrm{Xu}^{1 *}$
}

\begin{abstract}
Background: Oridonin, an ingredient used in traditional Chinese medicine, has been demonstrated to play an important role in antitumour effects, but the mechanism underlying its antitumour properties is still not clear.

Methods: To verify the anti-cancer effects of oridonin via a miRNA-dependent mechanism, comprehensive miRNA expression profiling of oridonin-treated BXPC-3 human pancreatic cancer cells was performed using a miRNA microarray assay based on Sanger miR-Base Release 20, followed by a validation using real-time PCR. MicroRNA target prediction and Gene Ontology and KEGG pathway analysis were performed to investigate possible pathways involved.

Results: The results showed that 105 miRNAs were significantly differentially expressed (signal reading $>500, p \leq 0.01$, |Log2-value| $\geq 1$ ) in oridonin-treated BXPC-3 human pancreatic cancer cells.

Conclusions: Our data indicates that oridonin inhibits BxPC-3 cells probably through regulating the expression of miRNAs. Interruption of miRNA profiling may provide new therapeutic methods for the clinical treatment of pancreatic cancer.
\end{abstract}

Keywords: Oridonin, miRNA, microarray, BxPC-3 pancreatic cancer cell

\section{Background}

Oridonin, a natural ent-kaurane diterpenoid compound, is isolated from the Chinese medicinal herb Rabdosia rubescens as well as other plants, such as Isodon trichocarpus and Isodon shikokianus. Oridonin has many physiological and pharmacological effects, including anti-inflammation, anti-bacterial and anti-tumour effects, and shows no obvious side effects when used for the treatment of various human diseases. Concerning anti-tumour effects, previous studies have reported that oridonin can induce cell growth inhibition, promote apoptosis and inhibit migration and invasion in many cancers [1-3]. Nevertheless, the mechanisms underlying the antitumour activity of oridonin have not been completely delineated.

\footnotetext{
* Correspondence: xujian832002@163.com

1 Medical Technology College, Zhejiang Chinese Medical University, Binwen Road, Binjiang District, Hangzhou 310053, Zhejiang Province, China
} Full list of author information is available at the end of the article
MicroRNAs (miRNAs) are a novel class of non-coding RNAs with lengths of 17-25 nucleotides (nt) that can regulate gene expression in eukaryotic organisms by pairing with target mRNAs to repress translation or cause degradation of multiple target mRNAs [4]. Recent studies have shown that miRNAs play crucial roles in many biological processes, such as development, cell growth, differentiation, apodosis and even tumouriogenesis [5,6]. Furthermore, miRNAs can function both as tumour suppressors and oncogenes and might be a potential therapeutic target in cancer. Recent publications have shown that correcting abnormal miRNAs in tumours can inhibit the function of the target mRNA in vivo in a mouse model $[7,8]$.

Traditional Chinese medicines have become a popular topic in relation to their potential anti-tumour properties. However, there are no available reports on oridonin which inhibits pancreatic cancer via miRNA regulation. In this study, we establish a sensitive microarray chip for miRNA expression profiling in BxPC-3 pancreatic cancer 
Table 1 miRNA regulation of oridonin in BxPC-3 cells

\begin{tabular}{|c|c|c|c|c|c|}
\hline Reporter name $^{a}$ & Log 2-value $^{b}$ & p-Value & Reporter name $^{a}$ & Log 2-value $^{\text {b }}$ & p-Value ${ }^{b}$ \\
\hline hsa-miR-513a-5p & 15.70 & $2.09 \mathrm{E}-66$ & hsa-miR-27b-5p & -16.93 & $0.00 E+00$ \\
\hline hsa-miR-3661 & 12.73 & $0.00 E+00$ & hsa-miR-205-3p & -16.63 & $0.00 E+00$ \\
\hline hsa-miR-4470 & 12.24 & $0.00 E+00$ & hsa-miR-4262 & -16.47 & $0.00 E+00$ \\
\hline hsa-miR-409-3p & 10.68 & $0.00 E+00$ & hsa-miR-499a-5p & -16.36 & $0.00 E+00$ \\
\hline hsa-miR-3197 & 10.32 & $0.00 E+00$ & hsa-miR-3934-3p & -16.32 & $0.00 E+00$ \\
\hline hsa-miR-5096 & 10.29 & $0.00 E+00$ & hsa-miR-193b-3p & -7.45 & $0.00 E+00$ \\
\hline hsa-miR-4267 & 10.13 & $0.00 E+00$ & hsa-miR-421 & -6.93 & $0.00 E+00$ \\
\hline hsa-miR-466 & 8.90 & $0.00 E+00$ & hsa-miR-10b-3p & -5.74 & $0.00 E+00$ \\
\hline hsa-miR-615-5p & 8.80 & $0.00 E+00$ & hsa-miR-7641 & -5.53 & $0.00 E+00$ \\
\hline hsa-miR-7108-5p & 8.13 & $0.00 E+00$ & hsa-miR-425-5p & -4.77 & $0.00 E+00$ \\
\hline hsa-miR-6791-5p & 7.92 & $0.00 E+00$ & hsa-miR-125b-5p & -4.38 & $0.00 E+00$ \\
\hline hsa-miR-1246 & 6.86 & $0.00 E+00$ & hsa-miR-200b-3p & -3.98 & $0.00 E+00$ \\
\hline hsa-miR-6807-5p & 6.57 & $1.38 \mathrm{E}-43$ & hsa-miR-3960 & -3.95 & $0.00 E+00$ \\
\hline hsa-let-7f-5p & 6.41 & $0.00 E+00$ & hsa-miR-132-3p & -3.55 & $0.00 E+00$ \\
\hline hsa-miR-1307-3p & 5.81 & $0.00 E+00$ & hsa-miR-361-5p & -3.34 & $0.00 E+00$ \\
\hline hsa-miR-4514 & 5.36 & 1.44E-59 & hsa-miR-3178 & -3.31 & $0.00 E+00$ \\
\hline hsa-miR-4472 & 5.22 & $0.00 E+00$ & hsa-miR-454-3p & -3.13 & $0.00 E+00$ \\
\hline hsa-miR-6126 & 5.04 & $0.00 E+00$ & hsa-miR-320b & -2.71 & $0.00 E+00$ \\
\hline hsa-miR-6073 & 4.60 & $1.24 \mathrm{E}-43$ & hsa-miR-455-3p & -2.62 & $0.00 E+00$ \\
\hline hsa-miR-4301 & 4.26 & $0.00 \mathrm{E}+00$ & hsa-miR-320e & -2.56 & $0.00 \mathrm{E}+00$ \\
\hline hsa-miR-4484 & 3.79 & $3.65 \mathrm{E}-71$ & hsa-miR-185-5p & -2.47 & $0.00 E+00$ \\
\hline hsa-miR-30c-1-3p & 3.65 & $0.00 E+00$ & hsa-miR-320c & -2.38 & $0.00 E+00$ \\
\hline hsa-miR-4447 & 3.59 & $2.47 \mathrm{E}-42$ & hsa-miR-4521 & -2.13 & $0.00 E+00$ \\
\hline hsa-miR-7977 & 3.56 & $0.00 \mathrm{E}+00$ & hsa-miR-320a & -2.10 & $0.00 E+00$ \\
\hline hsa-miR-5787 & 3.47 & 2.93E-51 & hsa-miR-193a-3p & -2.09 & $0.00 E+00$ \\
\hline hsa-miR-7150 & 3.44 & $2.24 \mathrm{E}-47$ & hsa-miR-320d & -2.04 & $0.00 E+00$ \\
\hline hsa-miR-4516 & 3.16 & $0.00 E+00$ & hsa-miR-92b-3p & -1.84 & $0.00 E+00$ \\
\hline hsa-miR-1273 g-3p & 3.06 & $0.00 E+00$ & hsa-let-7i-5p & -1.81 & $0.00 \mathrm{E}+00$ \\
\hline hsa-miR-6090 & 3.00 & $0.00 E+00$ & hsa-miR-183-5p & -1.79 & $0.00 E+00$ \\
\hline hsa-miR-494-3p & 2.98 & $1.06 \mathrm{E}-72$ & hsa-miR-365a-3p & -1.59 & $0.00 E+00$ \\
\hline hsa-miR-6786-5p & 2.87 & $1.26 \mathrm{E}-23$ & hsa-miR-186-5p & -1.54 & $0.00 E+00$ \\
\hline hsa-miR-6727-5p & 2.81 & $0.00 E+00$ & hsa-miR-125a-5p & -1.54 & $0.00 E+00$ \\
\hline hsa-miR-98-5p & 2.65 & $0.00 E+00$ & hsa-miR-151a-3p & -1.43 & $0.00 \mathrm{E}+00$ \\
\hline hsa-miR-668-3p & 2.64 & $6.84 \mathrm{E}-65$ & hsa-miR-224-5p & -1.42 & $0.00 E+00$ \\
\hline hsa-miR-1275 & 2.59 & $1.69 \mathrm{E}-50$ & hsa-miR-107 & -1.40 & $0.00 \mathrm{E}+00$ \\
\hline hsa-miR-6125 & 2.53 & 1.03E-49 & hsa-miR-93-5p & -1.34 & $0.00 E+00$ \\
\hline hsa-miR-6087 & 2.50 & $0.00 E+00$ & hsa-miR-3609 & -1.31 & $0.00 E+00$ \\
\hline hsa-miR-4505 & 2.31 & 1.03E-10 & sa-miR-103a-3p & -1.28 & $0.00 E+00$ \\
\hline ha-smiR-7110-5p & 2.26 & $3.03 \mathrm{E}-12$ & hsa-miR-4286 & -1.22 & $0.00 E+00$ \\
\hline hsa-miR-1260a & 2.14 & 1.31E-09 & hsa-miR-3607-5p & -1.20 & $0.00 E+00$ \\
\hline hsa-miR-6803-5p & 2.13 & $1.94 \mathrm{E}-10$ & hsa-miR-92a-3p & -1.19 & $0.00 E+00$ \\
\hline hsa-miR-29c-3p & 2.08 & $2.01 \mathrm{E}-13$ & hsa-miR-429 & -1.17 & $0.00 E+00$ \\
\hline hsa-miR-4466 & 2.04 & 3.57E-06 & hsa-miR-20a-5p & -1.15 & $0.00 \mathrm{E}+00$ \\
\hline hsa-miR-1973 & 1.93 & 7.49E-09 & hsa-miR-424-5p & -1.13 & $0.00 E+00$ \\
\hline
\end{tabular}


Table 1 miRNA regulation of oridonin in BxPC-3 cells (Continued)

\begin{tabular}{|c|c|c|c|c|c|}
\hline hsa-miR-4739 & 1.86 & 1.47E-04 & hsa-miR-17-5p & -1.09 & $0.00 E+00$ \\
\hline hsa-miR-3196 & 1.85 & $1.80 \mathrm{E}-15$ & hsa-miR-203a & -1.05 & $0.00 E+00$ \\
\hline hsa-miR-4497 & 1.76 & $1.16 \mathrm{E}-13$ & hsa-miR-574-3p & -1.04 & $0.00 E+00$ \\
\hline hsa-miR-378 g & 1.76 & $2.93 \mathrm{E}-03$ & hsa-miR-378c & -1.03 & $0.00 E+00$ \\
\hline hsa-miR-4459 & 1.73 & $5.05 \mathrm{E}-03$ & hsa-miR-423-5p & -1.01 & $0.00 E+00$ \\
\hline hsa-miR-3665 & 1.70 & $2.46 \mathrm{E}-11$ & & & \\
\hline hsa-miR-638 & 1.64 & $2.41 \mathrm{E}-04$ & & & \\
\hline hsa-miR-7704 & 1.63 & 4.06E-08 & & & \\
\hline hsa-let-7 g-5p & 1.54 & $1.18 \mathrm{E}-05$ & & & \\
\hline hsa-let-7e-5p & 1.52 & $3.00 \mathrm{E}-07$ & & & \\
\hline hsa-miR-4508 & 1.04 & $2.30 \mathrm{E}-08$ & & & \\
\hline hsa-miR-6089 & 1.03 & $2.17 E-19$ & & & \\
\hline Reporter name ${ }^{c}$ & Log2-value $^{b}$ & p-Value & Reporter name ${ }^{c}$ & Log 2-value $^{b}$ & p-Value \\
\hline hsa-miR-328-5p & 2.96 & $3.36 \mathrm{E}-18$ & hsa-miR-3943 & -16.15 & $0.00 E+00$ \\
\hline hsa-miR-5194 & 6.18 & $8.69 \mathrm{E}-39$ & hsa-miR-4536-3p & -16.08 & $0.00 \mathrm{E}+00$ \\
\hline hsa-miR-6085 & 2.55 & $2.40 \mathrm{E}-12$ & hsa-miR-1180-3p & -15.86 & $0.00 E+00$ \\
\hline hsa-miR-6880-5p & 2.69 & $1.08 \mathrm{E}-13$ & hsa-miR-3188 & -15.82 & $0.00 E+00$ \\
\hline hsa-miR-4791 & 14.87 & $2.29 \mathrm{E}-39$ & hsa-miR-1179 & -15.81 & $0.00 E+00$ \\
\hline hsa-miR-6124 & 3.00 & $1.28 \mathrm{E}-16$ & hsa-miR-3169 & -9.50 & $0.00 \mathrm{E}+00$ \\
\hline hsa-miR-1233-5p & 3.54 & $1.32 \mathrm{E}-20$ & hsa-miR-15b-3p & -7.42 & $0.00 E+00$ \\
\hline hsa-miR-765 & 2.56 & $9.53 \mathrm{E}-10$ & hsa-miR-301a-3p & -6.71 & $0.00 E+00$ \\
\hline \multirow[t]{9}{*}{ hsa-miR-4463 } & 2.34 & 1.77E-07 & hsa-miR-101-3p & -6.63 & $0.00 E+00$ \\
\hline & & & hsa-miR-3065-5p & -6.07 & $0.00 E+00$ \\
\hline & & & hsa-miR-625-5p & -3.97 & $0.00 \mathrm{E}+00$ \\
\hline & & & hsa-miR-24-2-5p & -3.06 & $0.00 \mathrm{E}+00$ \\
\hline & & & hsa-miR-128-3p & -2.86 & $0.00 E+00$ \\
\hline & & & hsa-miR-4289 & -2.65 & $0.00 E+00$ \\
\hline & & & hsa-miR-155-5p & -2.35 & $0.00 E+00$ \\
\hline & & & hsa-miR-197-3p & -2.21 & $0.00 E+00$ \\
\hline & & & hsa-miR-10a-5p & -2.08 & $0.00 E+00$ \\
\hline
\end{tabular}

${ }^{a}$ Transcripts showing strong signals (signal $\geq 500$; $\mid$ Log2-value $\mid \geq 1$ ).

boridonin/control.

'Transcripts showing weak signals ( $350<$ signal $<500$; $\mid$ Log2-value $\mid \geq 2$ ).

cells treated with oridonin to verify our hypothesis that oridonin alters the miRNA expression profile in pancreatic cancer, and we show that miRNAs have potential applications in the future clinical treatment of tumours.

\section{Methods}

\section{Cell culture}

The BxPC-3 human pancreatic cancer cell line was provided by the Institute of Biochemistry and Cell Biology, Shanghai Institute of Biological Sciences, Chinese Academy of Sciences (ATCC ${ }^{\circ}$ CRL1687 $^{\mathrm{Tu}}$ ). The cells were cultured in RPMI 1640 (GIBCO, NY, United States) culture medium containing $10 \%$ foetal bovine serum (FBS, Gibco), $300 \mathrm{mg} / \mathrm{L}$ glutamine, $100 \mathrm{U} / \mathrm{mL}$ penicillin and $100 \mu \mathrm{g} / \mathrm{mL}$ streptomycin in an incubator with $5 \% \mathrm{CO}_{2}$ at $37^{\circ} \mathrm{C}$. Cells in logarithmic growth phase were seeded in $60 \mathrm{~mm}$ dishes at a density of $4 \times 10^{4} \mathrm{cell} / \mathrm{cm}^{2}$ and incubated overnight. One group of these cells was subsequently treated with $87.8 \mu \mathrm{M}$ oridonin (Gracia Chemical Technology Company, LTD, 98\% purity, HPLC) dissolved in DMSO (final DMSO concentration in growth media is $0.1 \%$ ), and another was used as a blank control group cultured in medium containing 0.1\% DMSO for 24 hours. At least 3 independent experiments were performed.

\section{RNA isolation and miRNA microarray}

After 24 hours of treatment, total RNA (containing small RNAs) was extracted using the TRIzol LS reagent 
(Invitrogen Life Technologies) following the manufacturer's protocol. The microarray assay ( $\mu$ ParafloTM MicroRNA Microarray Assay) was performed by a service provider (LC Sciences), including quality control, labelling, chip hybridisation, signal amplification image acquisition and microarray data analysis. Hybridisation was performed overnight on a $\mu$ Paraflo microfluidic chip using a micro-circulation pump (Atactic Technologies) [9]. On the microfluidic chip, each detection probe consisted of a chemically modified nucleotide coding segment complementary to target microRNA (from miRBase, http://www.mirbase.org/) or other RNA (control or customer defined sequences) and a spacer segment of polyethylene glycol to extend the coding segment away from the substrate. The detection probes were made by in situ synthesis using PGR (photogenerated reagent) chemistry. The hybridization melting temperatures were balanced by chemical modifications of the detection

Table 2 miRNA expression in pancreatic cancer

\begin{tabular}{|c|c|c|c|}
\hline miRNA & Regulation & Source & Reference \\
\hline miR-17-5p & up & $\begin{array}{l}\text { pancreatic cancer cell lines } \\
\text { ( AsPC-1, KP-1 N, KP-3 and PANC-1 et al.) }\end{array}$ & {$[11,12]$} \\
\hline miR-10a & up & 15 pancreatic cancer cell lines & {$[12]$} \\
\hline miR-210 & up & pancreatic cancer patients & [13] \\
\hline miR-214 & up & pancreatic cancer tissues & [14] \\
\hline miR-15a & down & & \\
\hline miR-107 & up & MiaPACA-2 and PANC-1 cells & {$[15,16]$} \\
\hline miR-103 & up & & \\
\hline miR-29a & up & & \\
\hline miR-320 & up & & \\
\hline miR-375 & down & Panc-1, SW1990, BxpC3 and Patu8988 & {$[17]$} \\
\hline miR-483-3p & up & pancreatic cancer tissues & [18] \\
\hline miR-21 & up & pancreatic cancer pecimens and 14 pancreatic cancer cell lines & {$[19,20]$} \\
\hline miR-146a & down & Colo357 and Panc-1 & {$[21]$} \\
\hline miR-424-5p & up & Human PDAC Tissues and PDAC Cell Lines & [22] \\
\hline miR-155 & up & & \\
\hline $\operatorname{miR}-221$ & up & & \\
\hline Let-7 & down & Pancreatic ductal adenocarcinoma samples & [23] \\
\hline miR-126 & down & pancreatic tissue samples and cell lines & [24] \\
\hline miR-132 & up & Pancreatic adenocarcinoma (PDAC) tissues & [25] \\
\hline $\operatorname{miR}-212$ & up & & \\
\hline miR-96 & down & pancreatic cancer tissues and cell lines & [26] \\
\hline miR-217 & down & PDAC tissues and cell lines & {$[27]$} \\
\hline miR-494* & up & BxPC-3 cell & {$[28]$} \\
\hline $\operatorname{miR}-140$ & up & & \\
\hline miR-148a* & up & & \\
\hline miR-200b* & up & & \\
\hline $\operatorname{miR}-564^{*}$ & up & & \\
\hline miR-195* & up & & \\
\hline miR-637* & up & & \\
\hline miR-34a & down & MIA PaCa-2 and AsPC-1 cells & [29] \\
\hline miR-29c & down & normal pancreas and PDAC tissue & [30] \\
\hline miR-494 & down & & \\
\hline miR-615-5p & down & BXPC-3, CFPAC-1, SW1990, PANC-1 & [31] \\
\hline 95 miRNA (let-7-family, miR-7, miR-92 and miR-93 et al.) & up & BxPC-3 cell & [16] \\
\hline
\end{tabular}

*Passenger strand. 
probes. Hybridization used $100 \mathrm{~L}$ 6xSSPE buffer $(0.90 \mathrm{M}$ $\mathrm{NaCl}, 60 \mathrm{mM} \mathrm{Na}{ }_{2} \mathrm{HPO}_{4}, 6$ mM EDTA, pH 6.8) containing $25 \%$ formamide at $34^{\circ} \mathrm{C}$. After RNA hybridization, tagconjugating $\mathrm{Cy} 3$ dye were circulated through the microfluidic chip for dye staining. Fluorescence images were collected using a laser scanner (GenePix 4000B, Molecular Device) and digitized using Array-Pro image analysis software (Media Cybernetics). The data were analysed by first subtracting the background and then normalising the signals using a LOWESS filter (locally weighted regression). Then, the ratio of detected signals showing a $\log 2$ fold change $[\log 2$ (oridonin/control)] was used to define differentially expressed miRNAs, and Student's t-test was employed to calculate $P$ values.

\section{MiRNA target prediction and Gene Ontology and KEGG pathway analysis}

The prediction of miRNA targets was performed using the online software TargetScan (http://www.targetscan.org/), PicTar (http://pictar.mdc-berlin.de/cgi-bin/new_PicTar_vertebrate.cgi) and miRanda (http://www.microrna.org/microrna/home.do). The intersection of the results from these three types of software was taken as the final target genes of significantly differentially expressed miRNAs. Then, the target genes were analysed in terms of the annotation of their Gene Ontology (GO) categories and Kyoto Encyclopedia of Genes and Genomes (KEGG) pathways using Fisher's exact test.

\section{Reverse-transcription and Quantitative Real-time PCR}

To validate the microarray data, total RNA from the same preparation used for microarray analysis was reversetranscribed to cDNA in a Mycycler $^{\text {Tn }}$ Thermal Cycler (Bio-Rad, USA), and quantitative real-time polymerase chain reaction (qPCR) was performed in a Real-Time PCR Detector (Bio-Rad, USA) using the PrimeScript ${ }^{\text {mat }}$ miRNA qPCR Starter Kit Ver.2.0 (TaKaRa, Dalian, China), following the manufacturer's protocol. Each reaction was performed in a final volume of $25 \mu$ l containing $1 \mu \mathrm{l}$ cDNA, $0.4 \mu \mathrm{M}$ of each primer and $1 \times$ SYBR Premix Ex TaqII. The amplification program was as follows: denaturation at $95^{\circ} \mathrm{C}$ for $10 \mathrm{sec}$, followed by 40 cycles of denaturation at $95^{\circ} \mathrm{C}$ for $5 \mathrm{sec}$ and extension at $60^{\circ} \mathrm{C}$ for $20 \mathrm{sec}$, in which fluorescence was obtained. For quantification, RNU6B was used as the internal control, and expression levels of each mature miRNA were normalised using

Table 3 Differential expression of miRNAs in pancreatic cancer and pancreatic cancer induced by oridonin

\begin{tabular}{|c|c|c|c|c|}
\hline miRNA & Regulation & ${ }^{\mathrm{a}}$ Regulation reported in literature & Source in literature & Reference \\
\hline miR-205 & down & up & BxPC-3 cell & {$[16]$} \\
\hline miR-10b & down & up & BxPC-3 cell & {$[16]$} \\
\hline miR-125b & down & up & BxPC-3 cell & {$[16]$} \\
\hline miR-200b & down & up & BxPC-3 cell & {$[16]$} \\
\hline miR-132 & down & up & BxPC-3 cell & {$[16]$} \\
\hline miR-320 & down & up & MiaPACA-2 and PANC-1 cells & {$[15]$} \\
\hline miR-185 & down & up & BxPC-3 cell & {$[16]$} \\
\hline miR-92 & down & up & BxPC-3 cell & {$[16]$} \\
\hline miR-183 & down & up & BxPC-3 cell & {$[16]$} \\
\hline miR-186 & down & up & BxPC-3 cell & {$[16]$} \\
\hline miR-125a & down & up & BxPC-3 cell & {$[16]$} \\
\hline miR-151 & down & up & BxPC-3 cell & {$[16]$} \\
\hline miR-224 & down & up & BxPC-3 cell & {$[16]$} \\
\hline miR-107 & down & up & MiaPACA-2, PANC-1 and BxPC-3 cells & {$[15,16]$} \\
\hline miR-93 & down & up & BxPC-3 cell & {$[16]$} \\
\hline miR-103 & down & up & MiaPACA-2, PANC-1 and BxPC-3 cells & {$[15,16]$} \\
\hline miR-20a & down & up & BxPC-3 cell & {$[16]$} \\
\hline miR-424-5p & down & up & Human PDAC Tissues and PDAC Cell Lines & [22] \\
\hline miR-17-5p & down & up & 14 pancreatic cancer cell lines (AsPC-1, KP-1 N, KP-3 and PANC-1 et al.) & [11] \\
\hline miR-203 & down & up & BxPC-3 cell & [16] \\
\hline miR-29c-3p & up & down & normal pancreas and PDAC tissue & {$[30]$} \\
\hline miR-494 & up & down & & \\
\hline miR-615-5p & up & down & BxPC-3, CFPAC-1, SW1990 and PANC-1 & [31] \\
\hline
\end{tabular}

${ }^{a}$ Regulation reported in pancreatic cancer tissues/cells compared with normal pancreatic tissues/cells from the literature. 
the $2-^{\triangle \Delta C T}$ method [10]. All assays were performed in triplicate.

\section{Statistical analysis}

A $\log 2$ fold change [ $\log 2$ (oridonin/control)] was used to define differentially expressed miRNAs, and Student's ttest was employed to calculate $\mathrm{P}$ values. The target genes were analysed in terms of the annotation of their Gene Ontology (GO) categories and Kyoto Encyclopedia of Genes and Genomes (KEGG) pathways using Fisher's exact test. Results of realtime RT-PCR experiments are expressed as means \pm standard deviation (SD). Statistical comparisons were performed with the SPSS 17.0 software (Univariate Analysis of Variance) and statistical significance was considered for $P$ values lower than 0.05 .

\section{Results}

MiRNA expression was altered in BxPC-3 cells treated with oridonin

To study the responses of miRNAs to oridonin, microarray analysis of miRNA expression in BxPC-3 cells treated with oridonin was compared with the expression of miRNAs in DMSO treated cells. Only miRNAs showing significant expression among the oridonin treatments and their controls are reported (Table 1). As shown in Table 1, 105 reporters presented a strong response (signal reading $>500, \mathrm{p} \leq 0.01, \mid \log 2$-value $\left.{ }^{\mathrm{b}} \mid \geq 1\right)$ and significant regulation. Among these 105 miRNAs, 49 miRNAs were significantly down-regulated, whereas 56 were significantly up-regulated by oridonin. Among them, there are many new miRNAs whose function has been scarcely described in the literature.

Previous studies related to miRNA expression in human pancreatic cancer are collected and summarised in Table 2 for comparison and discussion. Results showed that the expression of some miRNAs was changed dramatically after treatment with oridonin, as shown in Table $3(20$ miRNAs, including miR-205, miR-10b, miR-125b, miR200b, miR-132, miR-320, miR-185, miR-424-5p, and miR-17-5p), which indicated that oridonin may influence $\mathrm{BxPC}-3$ pancreatic cancer cells through regulating miRNAs, though verifying this hypothesis will require further investigation.

\section{Target prediction and GO and KEGG pathway analyses}

It has been demonstrated that one miRNA could target more than one gene, whereas some genes were targets of more than one miRNA. To predict the target mRNAs of the differentially expressed miRNAs, we performed target prediction for the differentially expressed miRNAs identified in the BxPC-3 cells using three different types of online software: TargetScan, PicTar and miRanda. The intersection of three software's predictions was taken as the finally potential target genes.

GO and KEGG pathway analyses were performed on the target genes of the significantly differentially expressed miRNAs.

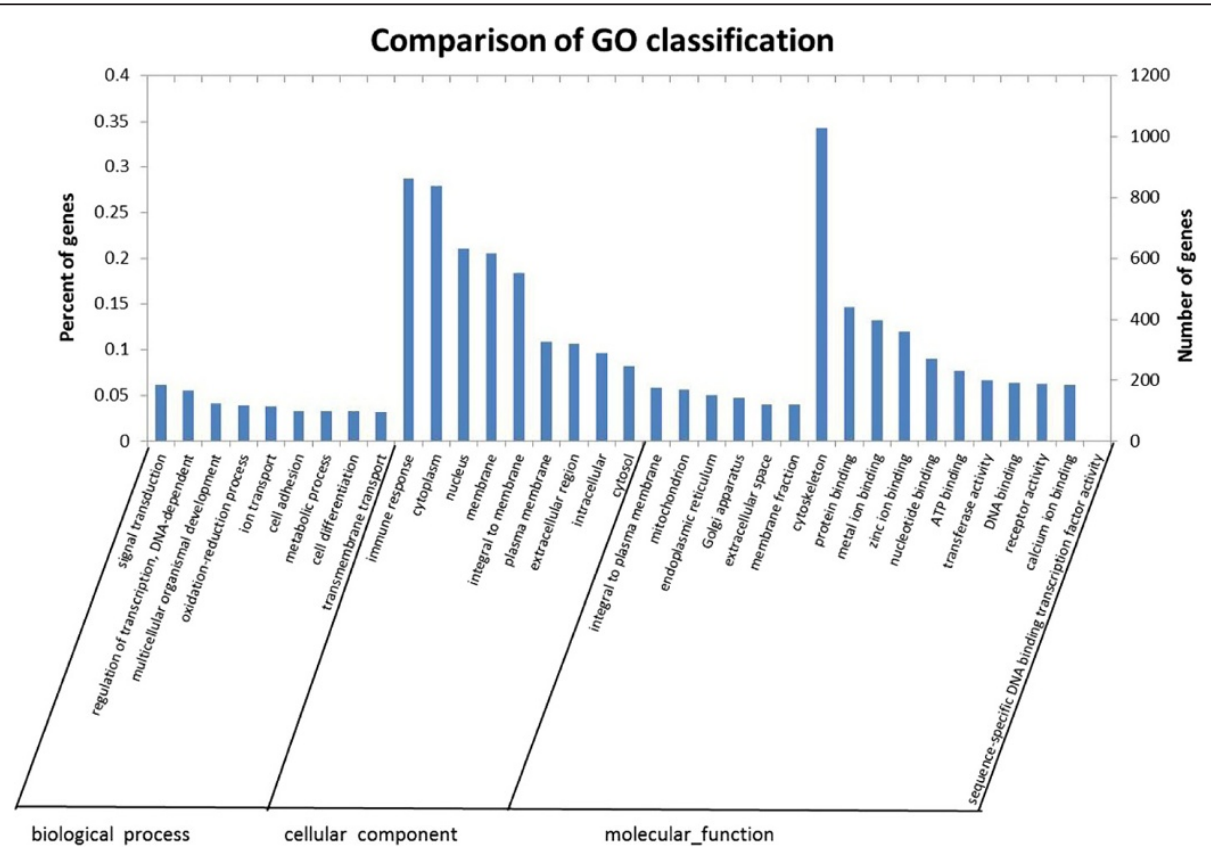

Figure 1 Distribution of GO categories for the predicted target genes of differentially expressed miRNAs identified in BxPC-3 cells treated with oridonin. The left vertical axis represents the percent of genes, the right vertical axis represents the number of genes and the horizontal axis represents the GO category, including biological processes, cellular components and molecular functions. 
The enriched GO annotations are shown in Figure 1. The results revealed that the significantly enriched predicted target genes were involved mainly in the following categories: biological processes (e.g., signal transduction, regulation of transcription, DNA-dependent and multicellular organismal development), cellular components (e.g., cytoplasm, nucleus, membrane, integral to membrane and plasma membrane) and molecular functions (protein binding, metal ion binding and zinc ion binding).
The KEGG pathway annotations of all of the target genes of the significantly differentially expressed miRNAs are shown in Table $4(\mathrm{P} \geq 0.05)$. KEGG is a major public database of biological pathways, and significant enrichment in KEGG categories can identify differentially expressed genes involved in the main biochemical metabolic pathways and signal transduction pathways. The results presented in Table 4 revealed that the influence of BxPC-3 pancreatic cancer cells by oridonin may

Table 4 KEGG pathway annotation of the targets of differentially expressed miRNAs identified in BxPC-3 cells treated with oridonin

\begin{tabular}{|c|c|c|c|c|c|c|}
\hline $\begin{array}{l}\text { Pathway } \\
\text { Id }\end{array}$ & Pathway description & $\begin{array}{l}{ }^{\mathrm{a} S} \text { gene } \\
\text { number }\end{array}$ & $\begin{array}{l}{ }^{\mathrm{b}} \text { TS gene } \\
\text { number }\end{array}$ & $\begin{array}{l}{ }^{\mathrm{C}} \mathrm{B} \text { gene } \\
\text { number }\end{array}$ & $\begin{array}{l}{ }^{\mathrm{d}} \text { TB gene } \\
\text { number }\end{array}$ & $P$ value \\
\hline 4080 & Neuroactive ligand-receptor interaction & 176 & 2158 & 206 & 2734 & 0.00899472 \\
\hline 5200 & Pathways in cancer & 174 & 2158 & 204 & 2734 & 0.010837484 \\
\hline 4010 & MAPK signaling pathway & 138 & 2158 & 155 & 2734 & 0.000542141 \\
\hline 4510 & Focal adhesion & 123 & 2158 & 141 & 2734 & 0.00651097 \\
\hline 4020 & Calcium signaling pathway & 118 & 2158 & 132 & 2734 & 0.000957212 \\
\hline 4144 & Endocytosis & 92 & 2158 & 104 & 2734 & 0.00754512 \\
\hline 4514 & Cell adhesion molecules (CAMs) & 79 & 2158 & 91 & 2734 & 0.03558939 \\
\hline 4142 & Lysosome & 73 & 2158 & 79 & 2734 & 0.000942336 \\
\hline 4640 & Hematopoietic cell lineage & 70 & 2158 & 76 & 2734 & 0.001553248 \\
\hline 4670 & Leukocyte transendothelial migration & 69 & 2158 & 78 & 2734 & 0.0203194 \\
\hline 4722 & Neurotrophin signaling pathway & 67 & 2158 & 76 & 2734 & 0.026182028 \\
\hline 4660 & T cell receptor signaling pathway & 65 & 2158 & 74 & 2734 & 0.033536383 \\
\hline 5414 & Dilated cardiomyopathy & 63 & 2158 & 68 & 2734 & 0.001810577 \\
\hline 5410 & Hypertrophic cardiomyopathy (HCM) & 62 & 2158 & 66 & 2734 & 0.000696228 \\
\hline 4350 & TGF-beta signaling pathway & 56 & 2158 & 62 & 2734 & 0.013956825 \\
\hline 4512 & ECM-receptor interaction & 56 & 2158 & 63 & 2734 & 0.029353732 \\
\hline 4912 & GnRH signaling pathway & 55 & 2158 & 62 & 2734 & 0.033519609 \\
\hline 5215 & Prostate cancer & 52 & 2158 & 56 & 2734 & 0.004141376 \\
\hline 5412 & $\begin{array}{l}\text { Arrhythmogenic right ventricular cardiomyopathy } \\
\text { (ARVC) }\end{array}$ & 52 & 2158 & 56 & 2734 & 0.004141376 \\
\hline 4730 & Long-term depression & 47 & 2158 & 51 & 2734 & 0.009668211 \\
\hline 5212 & Pancreatic cancer & 45 & 2158 & 50 & 2734 & 0.031740035 \\
\hline 4720 & Long-term potentiation & 44 & 2158 & 48 & 2734 & 0.015812816 \\
\hline 4662 & B cell receptor signaling pathway & 43 & 2158 & 48 & 2734 & 0.042316964 \\
\hline 5211 & Renal cell carcinoma & 41 & 2158 & 45 & 2734 & 0.025499631 \\
\hline 5220 & Chronic myeloid leukemia & 41 & 2158 & 45 & 2734 & 0.025499631 \\
\hline 4115 & p53 signaling pathway & 39 & 2158 & 43 & 2734 & 0.034764924 \\
\hline 5014 & Amyotrophic lateral sclerosis (ALS) & 37 & 2158 & 38 & 2734 & 0.001316211 \\
\hline 5213 & Endometrial cancer & 32 & 2158 & 34 & 2734 & 0.015598239 \\
\hline 520 & Amino sugar and nucleotide sugar metabolism & 26 & 2158 & 28 & 2734 & 0.046209141 \\
\hline 51 & Fructose and mannose metabolism & 22 & 2158 & 23 & 2734 & 0.030443267 \\
\hline 4330 & Notch signaling pathway & 20 & 2158 & 20 & 2734 & 0.008648864 \\
\hline
\end{tabular}

${ }^{a}$ The number of significantly differentially expressed genes matching KEGG pathways.

${ }^{\mathrm{b}}$ The total number of significantly differentially expressed genes.

'The number of genes matching KEGG pathways.

${ }^{\mathrm{d}}$ The total number of genes. 
be related to neuroactive ligand-receptor interactions, pathways involved in cancer, MAPK signalling pathways, focal adhesion, calcium signalling pathways and other factors, prompting further study on the mechanism of pancreatic cancer inhibition by oridonin.

\section{Validation of miRNA microarray data via Quantitative RT-PCR}

Among the significantly regulated miRNAs identified in the microarray assay, 4 miRNAs were selected for further validation via quantitative real-time PCR. The quantitative RT-PCR results showed that miR-409-3p was upregulated 2.04 times, miR-103a-3p was downregulated 1.85 times, miR-200b-3p was downregulated 2.22 times and miR-107 was downregulated 2.13 times in the oridonin treatment group compared with the control (Figure 2), which correlated well with the microarray results in Table 1.

\section{Discussion}

With the discovery of miRNAs, it has been shown that miRNAs can function as endogenous posttranscriptional gene regulators through binding to the $3^{\prime}$ untranslated region of target mRNAs, and emerging evidence suggests that miRNAs play an important role in regulating diverse biological processes. Abnormal expression of miRNAs is associated with many diseases, such as nervous system diseases, cardiovascular disease and cancer. Several studies have demonstrated that aberrant miRNA expression is involved in pancreatic cancer (Table 2).

Pancreatic cancer is one of the most lethal malignancies, characterised by its highly metastatic potential, worst prognosis and strong resistance to chemotherapy and

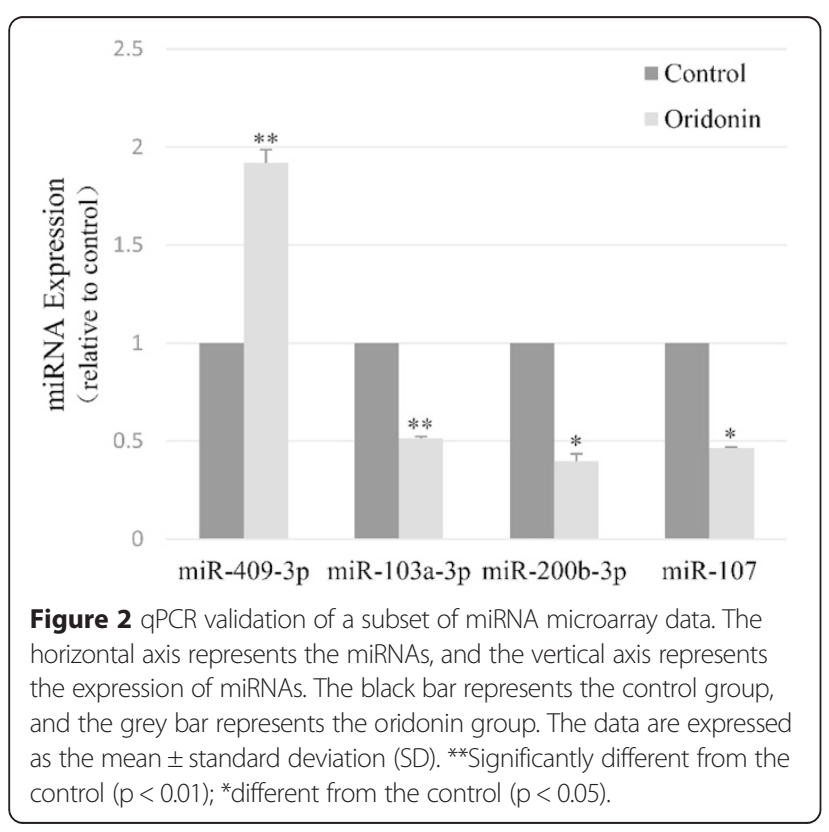

radiation therapy. The overall 5-year survival rate of pancreatic cancer is less than $5 \%$. Chemotherapy and radiation therapy are the main therapeutic methods used to treat such cancers, however, these treatments produce deleterious side effects. Therefore, there is an urgent need to find safer treatments. Recently, traditional Chinese medicines have become a "hot spot" in relation to their potential anti-tumour properties, although the mechanisms of such anti-tumour effects are not clear. Some studies showed that the anti-cancer mechanisms of the active ingredients of traditional Chinese medicines may be associated with miRNAs, which can be treated as targets for cancer therapies [32-34]. Previous studies revealed that oridonin can cause cell cycle arrest, induce apoptosis and enhance the antitumour activity of gemcitabine in pancreatic cancer [35-37]. In this study, the miRNA expression was profiled in BxPC-3 human pancreatic cancer cells treated with oridonin. MicroRNA results showed that 105 miRNAs were significantly altered by oridonin treatment (Table 1). Among them, many have been reported to be associated with tumorigenesis or cancer progression. For instance, miR-424-5p (Table 3) is overexpressed in human pancreatic cancer. Down-regulation of miR-424-5p inhibits cell proliferation, migration and invasion and increases cell apoptosis in PANC-1 cells [22]. In addition, miR-17-5p, which is related to a poor prognosis, is overexpressed in pancreatic cancer [11]. Both miR-424-5p and miR-17-5p were found to be down-regulated by oridonin in our microarray data, implying that oridonin may inhibit pancreatic cancer cell proliferation, migration, invasion, and induce apoptosis by down-regulating miR-424-5p and miR-17-5p.

Four miRNAs (miR-409-3p, miR-103a-3p, miR-200b-3p and miR-107) were chosen to validate the microarray assay via quantitative real-time PCR. PCR results showed a well correlation with the microarray results, confirming the significant difference between oridonin treated and untreated cells. It has been reported that epigenetic silencing of miR107 can regulate the expression of cyclin-dependent kinase 6 in pancreatic cancer [15]; while interfering miR-409-3p promotes tumour growth, the epithelial-to-mesenchymal transition (EMT) and bone metastasis [38]. miR-409-3p also suppresses the migration and invasion of bladder cancer T24 and 5,637 cells via targeting c-Met [39] and regulates cell proliferation and apoptosis by targeting PHF10 in SGC-7901 gastric cancer cells [40]. However, the effect of this miRNA on pancreatic cancer has rarely been described, similar to the situation for miR-103a-3p and miR-200b-3p. Based on the literature and our analysis on miRNA expression in cancer cells, we presume that these miRNAs likely play similar roles in pancreatic cancer, such as inhibiting cell proliferation, migration, invasion and inducing apoptosis. Thus, interruption of miRNA expression may be potential therapeutic targets for pancreatic cancer, although further studies are required to explore this possibility. 
For further investigation, Gene Ontology analysis and KEGG pathway annotation were applied. GO enrichment analysis showed that the mRNA clusters were significantly enriched for the categories that are essential for cell survival. A total of 31 enrichment pathways for predicted target genes were listed in Table 4. Among them, the top 5 signaling pathways were neuroactive ligand-receptor interactions, Pathways in cancer, MAPK, focal adhesion and calcium signalling pathways. The results showed that 176 predicted target genes are associated with neuroactive ligand-receptor interactions, 138 genes are associated with MAPK signaling pathways, while 118 genes are associated with calcium signalling pathways. Data from previous research suggest that oridonin can enhance the antitumour activity of gemcitabine in pancreatic cancer through the MAPK-p38 signalling pathway [36] and inhibit BxPC-3 cell growth through caspase signaling pathways [41], which verified the results of KEGG pathway annotation. In conclusion, The KEGG pathway annotation revealed that BxPC-3 pancreatic cancer cells may be influenced by oridonin through these pathways and provided new research directions.

\section{Conclusion}

In conclusion, the results of the present study provide new insights into the general mechanisms underlying the suppression of BxPC-3 cells by oridonin treatment and may provide new therapeutic methods for pancreatic cancer.

\section{Competing interests}

The authors declare that they have no competing interests.

\section{Authors' contributions}

ZG and JX Conceived and designed the experiments and drafted the manuscript. ZG and SL performed the experiments. ZG, XL and BX analysed the data. All authors read and approved the final manuscript.

\section{Acknowledgements}

This research was supported by the Zhejiang Province Project of Science Technology Department (NO.2014C33265 ), the Natural Science Foundation of Zhejiang Province (NO.LY14H160037) and the Natural Science Foundation of Jiangxi Province (NO. 20122BAB215042).

\section{Author details \\ ${ }^{1}$ Medical Technology College, Zhejiang Chinese Medical University, Binwen Road, Binjiang District, Hangzhou 310053, Zhejiang Province, China. ${ }^{2}$ School of Medicine, Jinggangshan University, Ji'an 343000, China. ${ }^{3}$ Department of General Surgery, Sir Run Run Shaw Hospital, School of Medicine, Zhejiang University, Hangzhou 310016, China.}

Received: 30 September 2014 Accepted: 30 March 2015 Published online: 14 April 2015

\section{References}

1. Ikezoe T, Chen SS, Tong X-J, Heber D, Taguchi H, Koeffler HP. Oridonin induces growth inhibition and apoptosis of a variety of human cancer cells. Int J Oncol. 2003;23(4):1187-93.

2. Wang S, Zhong Z, Wan J, Tan W, Wu G, Chen M, et al. Oridonin induces apoptosis, inhibits migration and invasion on highly-metastatic human breast cancer cells. Am J Chin Med. 2013;41(01):177-96.
3. Chen RY, Xu B, Chen SF, Chen SS, Zhang T, Ren J, et al. Effect of oridoninmediated hallmark changes on inflammatory pathways in human pancreatic cancer (BxPC-3) cells. World J Gastroenterol. 2014;20(40):14895-903.

4. Bartel DP. MicroRNAs: target recognition and regulatory functions. Cell. 2009;136(2):215-33.

5. Tsuchiya S, Okuno Y, Tsujimoto G. MicroRNA: biogenetic and functional mechanisms and involvements in cell differentiation and cancer. J Pharmacol Sci. 2006;101(4):267-70.

6. Cho WC. OncomiRs: the discovery and progress of microRNAs in cancers. Mol Cancer. 2007;6(1):60.

7. Krützfeldt J, Rajewsky N, Braich R, Rajeev KG, Tuschl T, Manoharan M, et al. Silencing of microRNAs in vivo with 'antagomirs'. Nature. 2005;438 (7068):685-9.

8. Felli N, Fontana L, Pelosi E, Botta R, Bonci D, Facchiano F, et al. MicroRNAs 221 and 222 inhibit normal erythropoiesis and erythroleukemic cell growth via kit receptor down-modulation. Proc Natl Acad Sci U S A. 2005;102 (50):18081-6.

9. Zhu Q, Hong A, Sheng N, Zhang X, Matejko A, Jun KY, et al. microParaflo biochip for nucleic acid and protein analysis. Methods Mol Biol. 2007;382:287-312.

10. Livak KJ, Schmittgen TD. Analysis of relative gene expression data using real-time quantitative PCR and the 2(-Delta Delta C(T)) Method. Methods. 2001;25(4):402-8.

11. Yu J, Ohuchida K, Mizumoto K, Fujita H, Nakata K, Tanaka M. MicroRNA miR-17-5p is overexpressed in pancreatic cancer, associated with a poor prognosis, and involved in cancer cell proliferation and invasion. Cancer Biol Ther. 2010;10(8):748-57.

12. Ohuchida K, Mizumoto K, Lin C, Yamaguchi H, Ohtsuka T, Sato N, et al. MicroRNA-10a is overexpressed in human pancreatic cancer and involved in its invasiveness partially via suppression of the HOXA1 gene. Ann Surg Oncol. 2012;19(7):2394-402.

13. Ho AS, Huang X, Cao H, Christman-Skieller C, Bennewith K, Le QT, et al. Circulating miR-210 as a Novel Hypoxia Marker in Pancreatic Cancer. Transl Oncol. 2010;3(2):109-13.

14. Zhang XJ, Ye H, Zeng CW, He B, Zhang H, Chen YQ. Dysregulation of miR-15a and miR-214 in human pancreatic cancer. J Hematol Oncol. 2010;3:46.

15. Lee KH, Lotterman C, Karikari C, Omura N, Feldmann G, Habbe N, et al. Epigenetic silencing of MicroRNA miR-107 regulates cyclin-dependent kinase 6 expression in pancreatic cancer. Pancreatology. 2009;9(3):293-301.

16. Zhang Y, Li M, Wang H, Fisher WE, Lin PH, Yao Q, et al. Profiling of 95 microRNAs in pancreatic cancer cell lines and surgical specimens by real-time PCR analysis. World J Surg. 2009:33(4):698-709.

17. Song S, Zhou J, He S, Zhu D, Zhang Z, Zhao H, et al. Expression levels of microRNA-375 in pancreatic cancer. Biomedical Rep. 2013;1(3):393-8.

18. Hao J, Zhang S, Zhou Y, Hu X, Shao C. MicroRNA 483-3p suppresses the expression of DPC4/Smad4 in pancreatic cancer. FEBS Lett. 2011;585(1):207-13.

19. Dillhoff M, Liu J, Frankel W, Croce C, Bloomston M. MicroRNA-21 is overexpressed in pancreatic cancer and a potential predictor of survival. J Gastrointest Surg. 2008;12(12):2171-6.

20. Moriyama T, Ohuchida K, Mizumoto K, Yu J, Sato N, Nabae T, et al. MicroRNA-21 modulates biological functions of pancreatic cancer cells including their proliferation, invasion, and chemoresistance. Mol Cancer Ther. 2009;8(5):1067-74.

21. Li Y, Vandenboom 2nd TG, Wang Z, Kong D, Ali S, Philip PA, et al. miR-146a suppresses invasion of pancreatic cancer cells. Cancer Res. 2010;70(4):1486-95.

22. Wu K, Hu G, He X, Zhou P, Li J, He B, et al. MicroRNA-424-5p suppresses the expression of SOCS6 in pancreatic cancer. Pathol Oncol Res. 2013;19(4):739-48.

23. Torrisani J, Bournet B, du Rieu MC, Bouisson M, Souque A, Escourrou J, et al. let-7 MicroRNA transfer in pancreatic cancer-derived cells inhibits in vitro cell proliferation but fails to alter tumor progression. Hum Gene Ther. 2009;20(8):831-44.

24. Hamada S, Satoh K, Fujibuchi W, Hirota M, Kanno A, Unno J, et al. MiR-126 acts as a tumor suppressor in pancreatic cancer cells via the regulation of ADAM9. Mol Cancer Res. 2012;10(1):3-10.

25. Park JK, Henry JC, Jiang J, Esau C, Gusev Y, Lerner MR, et al. miR-132 and miR-212 are increased in pancreatic cancer and target the retinoblastoma tumor suppressor. Biochem Biophys Res Commun. 2011;406(4):518-23.

26. Yu S, Lu Z, Liu C, Meng Y, Ma Y, Zhao W, et al. miRNA-96 suppresses KRAS and functions as a tumor suppressor gene in pancreatic cancer. Cancer Res. 2010;70(14):6015-25. 
27. Zhao WG, Yu SN, Lu ZH, Ma YH, Gu YM, Chen J. The miR-217 microRNA functions as a potential tumor suppressor in pancreatic ductal adenocarcinoma by targeting KRAS. Carcinogenesis. 2010;31(10):1726-33.

28. Hanoun N, Delpu Y, Suriawinata AA, Bournet B, Bureau C, Selves J, et al. The silencing of microRNA 148a production by DNA hypermethylation is an early event in pancreatic carcinogenesis. Clin Chem. 2010;56(7):1107-18.

29. Nalls D, Tang SN, Rodova M, Srivastava RK, Shankar S. Targeting epigenetic regulation of miR-34a for treatment of pancreatic cancer by inhibition of pancreatic cancer stem cells. PLoS One. 2011;6(8):e24099.

30. Szafranska AE, Davison TS, John J, Cannon T, Sipos B, Maghnouj A, et al. MicroRNA expression alterations are linked to tumorigenesis and non-neoplastic processes in pancreatic ductal adenocarcinoma. Oncogene. 2007;26(30):4442-52.

31. Gao W, Gu Y, Li Z, Cai H, Peng Q, Tu M, et al. miR-615-5p is epigenetically inactivated and functions as a tumor suppressor in pancreatic ductal adenocarcinoma. Oncogene. 2015;34(13):1629-40.

32. Sun M, Estrov Z, Ji Y, Coombes KR, Harris DH, Kurzrock R. Curcumin (diferuloylmethane) alters the expression profiles of microRNAs in human pancreatic cancer cells. Mol Cancer Ther. 2008;7(3):464-73.

33. Bae S, Lee EM, Cha HJ, Kim K, Yoon Y, Lee H, et al. Resveratrol alters microRNA expression profiles in A549 human non-small cell lung cancer cells. Mol Cells. 2011;32(3):243-9.

34. Li H, Hui L, Xu W, Shen H, Chen Q, Long L, et al. Triptolide modulates the sensitivity of $\mathrm{K} 562 / \mathrm{A} 02$ cells to adriamycin by regulating miR-21 expression. Pharm Biol. 2012;50(10):1233-40.

35. Bu HQ, Liu DL, Wei WT, Chen L, Huang H, Li Y, et al. Oridonin induces apoptosis in SW1990 pancreatic cancer cells via p53- and caspasedependent induction of p38 MAPK. Oncol Rep. 2014;31(2):975-82.

36. Bu HQ, Luo J, Chen H, Zhang JH, Li HH, Guo HC, et al. Oridonin enhances antitumor activity of gemcitabine in pancreatic cancer through MAPK-p38 signaling pathway. Int J Oncol. 2012;41(3):949-58.

37. Qi X, Zhang D, Xu X, Feng F, Ren G, Chu Q, et al. Oridonin nanosuspension was more effective than free oridonin on G2/M cell cycle arrest and apoptosis in the human pancreatic cancer PANC-1 cell line. Int J Nanomedicine. 2012;7:1793-804.

38. Josson S, Gururajan M, Hu P, Shao C, Chu GC, Zhau HE, et al. miR-409$3 p /-5 p$ promotes tumorigenesis, epithelial-to-mesenchymal transition, and bone metastasis of human prostate cancer. Clin Cancer Res. 2014;20(17):4636-46.

39. Xu X, Chen H, Lin Y, Hu Z, Mao Y, Wu J, et al. MicroRNA-409-3p inhibits migration and invasion of bladder cancer cells via targeting c-Met. Mol Cells. 2013;36(1):62-8

40. Li C, Nie H, Wang M, Su L, Li J, Yu B, et al. MicroRNA-409-3p regulates cell proliferation and apoptosis by targeting PHF10 in gastric cancer. Cancer Lett. 2012;320(2):189-97.

41. Xu B, Shen W, Liu X, Zhang T, Ren J, Fan Y, et al. Oridonin inhibits BxPC-3 cell growth through cell apoptosis. Acta Biochim Biophys Sin. 2015;47 (3):164-73.

\section{Submit your next manuscript to BioMed Central and take full advantage of:}

- Convenient online submission

- Thorough peer review

- No space constraints or color figure charges

- Immediate publication on acceptance

- Inclusion in PubMed, CAS, Scopus and Google Scholar

- Research which is freely available for redistribution

Submit your manuscript at www.biomedcentral.com/submit 